\title{
E-Commerce and Small Tourism Firms
}

\author{
Patrice Braun \\ University of Ballarat, Australia
}

\section{INTRODUCTION}

Today's networked economy is a strategic combination of many factors with electronic platforms and relationships underpinning competitive advantage. Enabled and driven by information and communication technologies (ICT) and connectivity, the networked economy is challenging the fundamental bases of established government frameworks, conventional business practices and traditional marketing disciplines. To achieve business success in this techno-economic paradigm requires new ways of thinking for all.

This paper examines regional development trends such as the growing importance of connectivity, electronic-commerce (e-commerce) and industry networks for global competitive advantage. Within that context it discusses issues facing small tourism firms in becoming part of the networked economy.

\section{REGIONAL NETWORKS}

A consistent pattern in today's economic business process is collaboration between firms, whereby emphasis is placed on networking, knowledge sharing and cooperation rather than competition [Marceau, 1998 \#186]. The adoption and diffusion of ICT and the Internet are integral components in today's business processes, as connectivity has increased our ability to connect and communicate with others, regardless of whether they are located locally, regionally, nationally or across the globe.

Research indicates that network building is not only a major new source of competitive advantage for any company, but a crucial asset to business survival and an essential global, and indeed, regional development requirement (Porter, 1998). Since the process of ICT-based information seeking, information distribution and knowledge sharing is interactive, it is believed that a firm's information channels or interpersonal networks play an important role.

In recent times regional development policy has undergone a paradigm shift from an exogenous or external focus to an endogenous or internal and relational network one [Storper, 1997 \#212]. Networking, community building and learning are portrayed as pivotal linkages for regional growth, whereby policy makers concerned with the performance of regional economies are seeking to foster a networked community culture [Asheim, 2001 \#213]. In geographic terms, networks can operate on an international, national, regional and local level. Examples of this network-building 
trend may be found internationally on the European Commission and the APEC action agendas (APEC, 2001). It is also reflected in Australian regional development policy, which, in taking it cues from global trends in regional development, portrays connectivity, networking, industry clustering, regional specialisation and capacity building as pivotal for regional growth (ALGA 2002).

As such, network formation is not a novel or emerging concept, but rather a recycled notion caught up in a new policy wave. Theoretical discussions on interfirm organisation can be found as far back as 1960 [Philips, 1960 \#270], although it would take several decades more until Miles and Snow (1992) [Miles, 1992 \#242] identified a significant movement towards the so-called network form. Since then, myriad network structures and traits have been discussed in the literature, including firm interdependence, trust between network partners, pitfalls of network alliances and issues surrounding change. The latter is of particular relevance in these rapidly changing times. Business networks are subject to both external changes, such as a transformation in the economic and technological climate, and internal ones, such as competition, issues of power and trust [Håkansson, 1995 \#310].

Connectivity and the Internet have added new dimensions to the concept of networked firms [Kisielnicki, 1998 \#528]. The advent of connectivity has boosted conventional reasons for interfirm networking, as the technology-enabled landscape provides the capacity for firms to collaborate with former competitors and potentially achieve "competitive co-evolution, enhanced by digital platform features" [Ordanini, 2001 \#536, 282]. The concept of clustering, another form of network formation, has also gained new prominence, as it can help create critical mass and facilitate the knowledge-based infrastructure needed for competitive advantage. Porter discusses competitive advantage as being "created and sustained through a highly localized process" [Porter, 1990 \#205, 19] and ascribes enduring competitive advantage in a global economy to local knowledge, relationships and motivation that cannot be duplicated by global partnering [Porter, 1998]. Thus, as a result of the networked economy, it may be said that organisational change can be expected throughout regions and across a number of industries, but especially in information-based industries such as the tourism industry.

\section{TOURISM AND TECHNOLOGY}

Being among the two largest, most rapidly growing and most dynamic industries, tourism and technology have become inextricably linked and together they are changing the way society operates [Werthner, 1999 \#52]. The tourism industry has always relied heavily on information. In fact, until a tourist gets to his or her chosen destination, tourism is information rather than a physical product. While tourism services are produced and consumed in a physical world set in a regional or local context, purchase of a tourism product is generally based on information received through direct or intermediary market channels; prior knowledge; word of mouth; and perceptions of trust and service quality [Beirne, 1999 \#62]. The nature of the tourism product being information-based makes it a search product, which is evaluated by

Encyclopedia of Developing Regional Communities with Information and Communication Technology (2006), Stewart Marshall, Wal Taylor \& Xinghuo Yu (Eds). Idea Group

Reference, Hershey, PA, pp 233-238. 
perusing product-related information. Being dependent on effective information flows makes the tourism product a complex one, as is “....almost entirely dependent upon representations (such as pictures in brochures) and descriptions to help consumers make a purchase decision [Laubenheimer, 1999 \#59, 279].

Tourism intermediaries typically fulfil functions such as pre-sorting and structuring tourism product information, providing a place for the supply and demand side to meet each other and reducing uncertainty [Wynne, 2001 \#74, 422]. Travel agents have traditionally been high profile intermediaries between travel suppliers and consumers, selling the tourism product to consumers for which they derive a sales commission. Apart from their customer service role, a travel agent's product knowledge and expertise is the value added for the customer. Destination marketing organisations, such as regional and local tourist information centres, also perform an intermediary (booking) role, most often between consumers and small tourism enterprises (SME) [Inkpen, 1998 \#60].

Enter information technology and the Internet. The Internet has the ability to provide a highly suitable and major new market channel for tourist products, because it can display information and pictures. The travel and tourism sector to a large degree depends on business-to-consumer (B2C) e-commerce activity. The Internet can create a direct link between a worldwide supplier community and equally dispersed consumers [Inkpen, 1998 \#60]. Speed is also crucial in the travel industry and the Internet can provide an instant confirmation response to an inquiry such as flight or room availability. The influence of ICT on tourism product perusal and purchase is evident in the proliferation of travel/tourism sites on the web [Bernstein, 1999 \#77]. A search engine query on travel and tourism will return an incredible 15 million results, which includes information on anything from outback tours to deep sea adventures to bed and breakfast stays around the globe. To date the sale of online airline tickets constitutes the largest part of e-commerce related travel business. In North America alone, travel purchases before 2000 accounted for US\$4 billion in sales with forecasts for 2003 ranging up to US\$29 billion [Pappas, 2001 \#51].

With increasing ICT literacy of prospective customers, consumer expectation of easy access to tourism product is rising. Such consumer expectations are likely to increase pressure on product providers to either offer instantaneous product information satisfaction or lose potential customers [Buhalis, 1998 \#88]. The emergence of electronic markets and the ICT literacy of prospective customers, who have the opportunity for tourism product users to bypass intermediaries in the travel value chain by booking directly on the web, have kindled questions about the necessity and ability of small tourism firms to become part of the networked economy.

In many parts of the world, small and medium sized firms (SMEs) and micro tourism enterprises make a substantial contribution to regional economies. In this context tourism SMEs are an important instrument for raising the profile of a region. At the same time the requirements of the globalised economy raises the bar for tourism

Encyclopedia of Developing Regional Communities with Information and Communication Technology (2006), Stewart Marshall, Wal Taylor \& Xinghuo Yu (Eds). Idea Group Reference, Hershey, PA, pp 233-238. 
SMEs in all regions with expectations towards a high capacity for ICT innovation, even on a relatively small scale (ALGA 2002)..

While connectivity has the potential to increase regionally based tourism SMEs' visibility in the market place, small tourism enterprises have been facing difficulties embracing ICT and competing with their larger counterparts. Small tourism firms, much like other small firms, often lack the time, skills and resources needed to implement ICT (Buhalis \& Main, 1998). Micro and small tourism enterprises generally consider themselves outside the tourism industry, despite the fact that most of their customers are tourists [Evans, 2001 \#79]. Their size being their main disadvantage [Werthner, 1999 \#52], tourism SMEs tend to be over-dependent on intermediaries for product marketing and distribution and therefore have limited bargaining power in the distribution channel [Buhalis, 1998 \#54; Werthner, 1999 \#52]. Other barriers may be technology itself, where the lifestyle choice of owneroperators often entails a negative attitude towards ICT [Evans, 1999 \#72]. Besides, many tourism SMEs are located in peripheral regions where the ICT infrastructure, especially broadband, can still be inadequate or prohibitively expensive due to limited demand (Anckar \& Walden, 2001). In some cases this leads to a perceived lack of value of ICT and the Internet.

A New Zealand study of micro tourism firms identified the education and professional background of owner-operators to be significant barriers [Ateljevic, 1999 \#87],

pointing to a widespread consensus that industry preparedness in terms of training falls well short of the requirements to operate within a now ICT-driven sector [Baines, 1998 \#99; Danielle, 1999 \#98; Jameson, 2000 \#100]. Presenting the results of a three-year study on the usage of and plans for ICT training in a fragmented and SME-dominated European tourism sector, Evans et al (2001) note that small tourism firms may well remain lost in the electronic marketplace, unless they are assisted in the usage of ICT tools and acquire the skills needed to participate in the digital economy [Evans, 2001 \#79].

Being small businesses, tourism SMEs have rather limited marketing means and, despite the information-intense nature of the tourism product, are not necessarily up to the task of marketing themselves online (Buhalis, 1999). As individual enterprises with limited marketing budgets, most small firms fail to focus on marketing planning and market intelligence. Preoccupied with the operational running of their business, smaller operators have tended to approach their markets “...less formally and more intuitively from their detailed, close contact with their guests” [Main, $1999 \# 106$, 349]. To make matters worse, a micro tourism website is easily overshadowed by the plethora of mega tourism websites such as Travelocity and Expedia currently available on the Internet. To summarise, due to their nature and scale, small tourism firms lack the advantages of larger tourism enterprises such as resources, know-how and access to global distribution systems and other network support systems. At the same time, there is increasing pressure on small firms to offer web-based product information.

Encyclopedia of Developing Regional Communities with Information and Communication Technology (2006), Stewart Marshall, Wal Taylor \& Xinghuo Yu (Eds). Idea Group Reference, Hershey, PA, pp 233-238. 


\section{REGIONAL TOURISM NETWORKS}

Although ICT appears to threaten the very existence of small tourism firms without resources, know-how, and access to distribution channels, regional network formation may provide a solution for small tourism firms.

The interrelationship between tourism and technology is not a recent phenomenon; it dates back to the early days of computing and the impact of post 1960s mass travel. To date, however, travel industry networks that pursue web-enabled capabilities have been largely driven by the airline industry seeking to extend its global reach through strategically-aligned partnerships, global booking and distribution systems and costsaving synergies in services such as baggage handling, catering, engineering and maintenance (Pappas, 2001). Thus the Internet provides big players with far-reaching business-to-consumer (B2C) as well as business-to-business (B2B) opportunities to enhance and develop specialised relationships with their customer base. However, as a result of the networked economy, organisational changes are now expected to affect the entire tourism industry, which is predominantly made-up of small enterprises.

Almost a decade ago, in addressing tourism and technology, Poon (1993) stressed that to avoid isolation, achieve economies of scale, and maximise destination benefits, there would be no place in the future for the stand-alone tourism SME; and that networking would allow small tourism firms to pool their resources, reduce operating costs, increase know-how, and formulate strategic marketing plans (Poon, 1993). Research further suggests that small tourism enterprises form a natural amalgam, because the fortunes of the destination and the firms are closely intertwined. Buhalis and Cooper (1998) believe that tourism SMEs tend to cooperate rather than compete by formulating value-added networks of product and service delivery (e.g., by referring customers to each other), thus enhancing tourist satisfaction (Buhalis \& Cooper, 1998). Anckar and Walden (2001) similarly advocate that a network or information technology infrastructure is not only useful, but indeed essential to bring small tourism firms and cyber customers together; as well as to increase the willingness of cyber customers to purchase tourism products from smaller regional suppliers (Anckar \& Walden, 2001). In addition, mapping and understanding the processes that take place in existing tourism networks has the potential to speed up technology adoption and create effective collaborative network outcomes (Braun, 2004).

Cooperative marketing research has long confirmed that networking in the form of cooperative marketing can add value to a destination (Palmer \& Bejou, 1995; Palmer \& McCole, 2000; Williams \& Palmer, 1999). Traditionally, such cooperation has been used in the production of joint marketing brochures and shared stands at trade shows. The advent of the Internet and related regional development trends offer expanded opportunities for cooperative marketing. Tourism operators on both the macro (destination) and micro (individual tourism SME) level are starting to see the potential benefits of using web technologies for cooperative marketing and transaction purposes

\section{5}

Encyclopedia of Developing Regional Communities with Information and Communication Technology (2006), Stewart Marshall, Wal Taylor \& Xinghuo Yu (Eds). Idea Group

Reference, Hershey, PA, pp 233-238. 
(Main, 2002). Indeed, in the wake of information technology and new regional network initiatives, cooperative marketing websites are proliferating (Tourism Victoria 2003).

Interesting cooperative marketing and e-commerce opportunities notwithstanding, tourism SME participation in networks is far from guaranteed. Joining a network constitutes a considerable leap for small tourism firms. Barriers to entering networks have been put down to cultural factors on the one hand and lack of resources (time, staff, opportunity) on the other [Evans, 1999 \#89]. Evans (1999) particularly singles out aversion to joining groups, attending training sessions and meetings, which "may be antithetic to the stress that owner-managers place on autonomy and independence the main reason they went into business on their own in the first place" [Evans, 1999 \#89, 380]. Small firms tend to limit their external contacts to compulsory contacts, e.g., local government and tax agencies and direct support actors and agencies, e.g., customers, accountants and banks.

A research project undertaken with small tourism firms in North London showed that the greatest interest in networking came from those businesses that had the strongest links to the local economy [Evans, 1999 \#89]. The development of a shared destination website proved to be attractive to local tourism operators in terms of joint marketing and securing new business. However, the project also highlighted the firms' relatively underdeveloped knowledge of ICT itself and a varying degree of reluctance within the sector in terms of joining a network. Although notable research into tourism-specific cooperative use of the Internet as a marketing tool and ecommerce remains in its infancy [Beckendorff, 2000 \#124], to date the greatest interest in using ICT networks in the tourism sector has been to develop joint online marketing initiatives, indicating that many tourism SMEs have yet to embrace webbased e-commerce processes. Initial value for tourism SMEs lies in the debunking of ICT jargon, cutting connectivity cost, gaining online visibility, gaining trust in network structures, and obtaining e-commerce skills through linkages with local partners. Continued incentives and support will help tourism SME to get comfortable and take mental, physical and virtual possession of a shared ICT domain (Braun, 2002).

Tourism networks, like all networks, should be seen as complex and dynamic organisms with ever-changing actors and external economic and technological influences. ICT-based network formation involves an intensive learning process for every actor involved in the network. This requires strong social ties within the network, fluid communications flows, strong leadership and commitment to the network. In certain instances network formation and small business collaboration will need to be fostered through the offering of incentives and training. An appropriate balance also needs to be struck between autonomy and competition in evolving small tourism firms from an individualistic business to a network culture. By drawing on a broader skill base through the forging of new partnerships between regional ecommerce experts and marketing bodies, issues such as product and market reach can be addressed. Similarly, inclusion of small firms in global marketing and distribution

Encyclopedia of Developing Regional Communities with Information and Communication Technology (2006), Stewart Marshall, Wal Taylor \& Xinghuo Yu (Eds). Idea Group Reference, Hershey, PA, pp 233-238. 
systems may help advance tourism regions, and thus small tourism firms, into the global marketplace and help forge new destination management partnerships.

\section{CONCLUSION}

Today, ICT and the Internet enable tourism SMEs and tourism networks such as regional destination marketing organisations (DMO) to better cope with increased information flows, getting the marketing message out to the public and selling their product online through e-commerce.

The Internet has the ability to provide a highly suitable and major new market channel for tourist product, because it can create a direct link between regional tourism SMEs and worldwide consumers. By using the Internet as an online network and cooperative market channel, tourism destinations, marketing organisations and individual tourism SMEs in regions all over the world have an opportunity to contribute to regional development and keep up with a now predominantly ICT-based industry.

For many small tourism firms, joining an ICT-based network and embracing ecommerce will entail radical new ways of business thinking, which will take time. As Gretzel et al. (2000) have pointed out, success in the new economy is more about change in approach than about technology itself (Gretzel, Yuan, \& Fesenmaier, 2000).

\section{REFERENCES}

Australian Local Government Association (ALGA) (2002) State of the Regions 2001. Overview: http://www.alga.com.au/SOR-Overview_2002.htm

Anckar, B., \& Walden, P. (2001). Introducing Web Technology in a Small Peripheral Hospitality Organization. International Journal of Contemporary Hospitality Management, 13(5), 241-250.

APEC. (2001). Beijing Initative on APEC Human Capacity Building. Retrieved July 10, 2001, from http://www.apec.org

Beirne, E., \& Curry, P. (1999). The Impact of the Internet on the Information Search Process and Tourism Decision Making. In D. Buhalis \& W. Schertler (Eds.), International Conference on Information and Communication Technologies in Tourism 1999 (pp. 87-97). Innsbruck, Austria: Springer-Verlag.

Bernstein, J., \& Awe, S. C. (1999). "Wired Travelers": travel and tourism Web sites. Reference Services Review, 27(4), 364-375.

Braun, P. (2004).Regional Innovation and Tourism Networks: the nexus between ICT diffusion and change in Australia, Information Technology \& Tourism, Volume 6, 4, 35-47.

Braun, P. (2002). Networking Tourism SMEs: E-Commerce and E-marketing Issues in Regional Australia. Information Technology \& Tourism, 5(1), 13-24.

Encyclopedia of Developing Regional Communities with Information and Communication Technology (2006), Stewart Marshall, Wal Taylor \& Xinghuo Yu (Eds). Idea Group

Reference, Hershey, PA, pp 233-238. 
Buhalis, D. (1999). Information Technology for Small and Medium-Sized Tourism Enterprises: Adaptation and Benefits. Information Technology \& Tourism, 2(1-4), 79-95.

Buhalis, D., \& Cooper, C. (1998). Competition or Cooperation? Small and mediumsized tourism enterprises at the destination. In E. Laws \& et al (Eds.), Embracing and Managing Change in Tourism. London: Routledge.

Buhalis, D., \& Main, H. (1998). Information technology in peripheral small and medium hospitality enterprises: strategic analysis and critical factors. International Journal of Contemporary Hospitality Management, 10(5), 198202.

DETR (2000). Regional Government in England: A Preliminary Review of Literature and Research Findings. Department of Environment, Transport and Regions, United Kingdom.

Evans, G., Bohrer, J., \& Richards, G. (2001). Small is Beautiful? ICT and Tourism SMEs- a Comparative European Study. Information Technology \& Tourism, 3(3/4), 139-153.

Gretzel, U., Yuan, Y., \& Fesenmaier, D. R. (2000). Preparing for the new economy: advertising strategies and change in destination marketing organizations. Journal of Travel Research, 39(2), 146-155.

Main, H. C. (2002). The Expansion of Technology in Small and Medium Hospitality Enterprises with a Focus on New Technology. Information Technology \& Tourism, 4(3/4), 167-174.

Marceau, J., \& Dodgson, M. (1998). Systems of Innovation. Retrieved 26 October, 2000, from online: http://www.isr.gov.au/industry/ summit/reference/learned_group/index.html

Palmer, A., \& Bejou, D. (1995). Tourism destination marketing alliances. Annals of Tourism Research, 22(3), 616-629.

Palmer, A., \& McCole, P. (2000). The role of electronic commerce in creating virtual tourism destination marketing organisations. International Journal of Contemporary Hospitality Management, 12(3), 198-204.

Pappas, G. (2001). The Next Chapter in Business-to-Consumer E-Commerce: The Impact of the Internet on the airline industry. Retrieved October 18, 2001, from www.bcg.com

Poon, A. (1993). Tourism, Technology and Competitive Strategies. Oxford: CAB International.

Porter, M. E. (1998). On Competition. Boston, MA: Harvard Business School.

Williams, A. P., \& Palmer, A. (1999). Tourism destination brands and electronic commerce: towards synergy. Journal of Vacation Marketing, 5(3), 263-275.

KEY TERMS

APEC

Connectivity
Asia Pacific Economic Cooperation

The ability to link to the Internet via a computer

8

Encyclopedia of Developing Regional Communities with Information and Communication Technology (2006), Stewart Marshall, Wal Taylor \& Xinghuo Yu (Eds). Idea Group

Reference, Hershey, PA, pp 233-238. 
ICT Information and communication technologies. The technology and tools used to transfer information and speed up communication processes.

Intermediary Person or organisation performing a (booking) role between consumers and business

Market Channel A publicly accessible means such as a newspaper, magazine, trade show, radio, billboards, television or the Internet, used to advertise and market products.

SMEs

Small and medium size enterprises. Refers to enterprises with a specific number of staff. A small size enterprise generally refers to firms with less than 20 employees.

Web-enabled Business systems that are supported by Internet technologies

Encyclopedia of Developing Regional Communities with Information and Communication Technology (2006), Stewart Marshall, Wal Taylor \& Xinghuo Yu (Eds). Idea Group Reference, Hershey, PA, pp 233-238. 